\title{
A systematic review of the literature examining the diagnostic efficacy of measurement of fractionated plasma free metanephrines in the biochemical diagnosis of pheochromocytoma
}

\author{
Anna M Sawka*1,2,3, Ally PH Prebtani2,4, Lehana Thabane ${ }^{5,6}$, Amiram Gafni ${ }^{6}$, \\ Mitchell Levine ${ }^{1,5,6}$ and William F Young $\mathrm{Jr}^{7}$
}

\begin{abstract}
Address: ${ }^{1}$ Department of Internal Medicine, St. Joseph's Healthcare, Hamilton, Ontario, L8N 4A6, Canada, ${ }^{2}$ Division of Endocrinology and Metabolism, McMaster University, Hamilton, Ontario, L8N 3Z5, Canada, ${ }^{3}$ Hoffmann-La Roche Research Fellow in Health Economics, McMaster University, Hamilton, Ontario, L8N 3Z5, Canada, ${ }^{4}$ Department of Internal Medicine, Hamilton General Hospital, Hamilton, Ontario, L8L 2X2, Canada, ${ }^{5}$ Centre for Evaluation of Medicines, St. Joseph's Healthcare, Hamilton, Ontario, L8N 1G6, Canada, ${ }^{6}$ Department of Clinical Epidemiology and Biostatistics, McMaster University, Hamilton, Ontario, L8N 3Z5, Canada and ${ }^{7}$ Division of Endocrinology, Metabolism, Nutrition, and Internal Medicine, Mayo Clinic, Rochester, MN, 55905, USA
\end{abstract}

Email: Anna M Sawka* - sawkaam@yahoo.com; Ally PH Prebtani - sawkaam@yahoo.com; Lehana Thabane - sawkaam@yahoo.com; Amiram Gafni - sawkaam@yahoo.com; Mitchell Levine - sawkaam@yahoo.com; William F Young - sawkaam@yahoo.com

* Corresponding author

Published: 29 June 2004

BMC Endocrine Disorders 2004, 4:2 doi:10.1186/1472-6823-4-2

This article is available from: http://www.biomedcentral.com/1472-6823/4/2

(c) 2004 Sawka et al; licensee BioMed Central Ltd. This is an Open Access article: verbatim copying and redistribution of this article are permitted in all media for any purpose, provided this notice is preserved along with the article's original URL.

\begin{abstract}
Background: Fractionated plasma metanephrine measurements are commonly used in biochemical testing in search of pheochromocytoma.

Methods: We aimed to critically appraise the diagnostic efficacy of fractionated plasma free metanephrine measurements in detecting pheochromocytoma. Nine electronic databases, meeting abstracts, and the Science Citation Index were searched and supplemented with previously unpublished data. Methodologic and reporting quality was independently assessed by two endocrinologists using a checklist developed by the Standards for Reporting of Diagnostic Studies Accuracy Group and data were independently abstracted.
\end{abstract}

Results: Limitations in methodologic quality were noted in all studies. In all subjects (including those with genetic predisposition): the sensitivities for detection of pheochromocytoma were $96 \%-100 \%$ (95\% Cl ranged from $82 \%$ to $100 \%$ ), whereas the specificities were $85 \%-100 \%(95 \% \mathrm{Cl}$ ranged from $78 \%$ to $100 \%$ ). Statistical heterogeneity was noted upon pooling positive likelihood ratios when those with predisposition to disease were included $(p<0.00 \mathrm{I})$. However, upon pooling the positive or negative likelihood ratios for patients with sporadic pheochromocytoma (n $=191)$ or those at risk for sporadic pheochromocytoma $(n=718)$, no statistical heterogeneity was noted $(p=0.4)$. For sporadic subjects, the pooled positive likelihood ratio was $5.77(95 \% \mathrm{Cl}=4.90$, $6.8 \mathrm{I})$ and the pooled negative likelihood ratio was $0.02(95 \% \mathrm{Cl}=0.0 \mathrm{I}, 0.07)$.

Conclusion: Negative plasma fractionated free metanephrine measurements are effective in ruling out pheochromocytoma. However, a positive test result only moderately increases suspicion of disease, particularly when screening for sporadic pheochromocytoma. 


\section{Background}

Pheochromocytoma is a rare tumor of chromaffin cells in the adrenal medulla or sympathetic ganglia, which can present clinically as hypertension, spells (of hypertension, palpitations, headache, or other symptoms), or an incidentally discovered adrenal mass seen on imaging studies [1-5]. The annual incidence is only 1.55 to 8 cases per million [6-10], although rare genetic mutations can increase predisposition [11,12]. As many common clinical syndromes (such as refractory hypertension) can mimic symptoms and signs of pheochromocytoma, the condition is "frequently sought and rarely found" $[2,13,14]$.

The biochemical screening test used for diagnosing pheochromocytoma is institution and laboratory-dependent with variable performance, and an "ideal" test for pheochromocytoma has been sought over the years as false or uninterpretable results are not uncommon with some traditional tests [1,14-47]. Recently, measurement of fractionated plasma free metanephrines by high performance liquid chromatography and electrochemical detection has been endorsed by investigators at the National Institute of Health (NIH) as the single best test for biochemical screening for pheochromocytoma [48-61]. The objective of the current study is to systematically review the literature to determine the diagnostic efficacy of measurements of fractionated plasma metanephrines in detection of pheochromocytoma.

\section{Methods}

\section{Study selection}

We included studies of adults who underwent measurement of fractionated plasma free metanephrines for the purpose of diagnostic testing. All studies had a "methods" section and included at least 10 subjects with pheochromocytoma (or paraganglioma) and at least 10 subjects without the diagnosis. Studies in which more than a third of subjects were below the age of 18 years or focussing on patients with end stage renal disease were excluded. In the case of multiple concurrent publications from the same research group, only the article describing the largest number of subjects tested were included. Updated unpublished data obtained from authors was included. The term pheochromocytoma refers to adrenal pheochromocytomas and extra-adrenal paragangliomas. The method of Lenders was used for measurement of fractionated plasma metanephrines [49]. Plasma metanephrine measurements in the setting of clonidine-suppression or glucaconstimulation were excluded.

\section{Data sources}

The following electronic databases were searched with no language restrictions: Medline (1989-February 2003), Pre-Medline February 21, 2003, Cochrane Database for Systematic Reviews, American College of Physicians Jour- nal Club (September 1991-October 2002), Database of Abstracts of Reviews, the Controlled Clinical Trials Database, CANCERLIT (1975-2002), Healthstar 1975December 2002, and CINAHL 1982 to week 1 February, 2003. The search strategy used incorporated the MESH heading "metanephrine" or the textword roots of "metanephrine" or "normetanephrine", as well as the textword "plasma", and the MESH headings of "paraganglioma", "pheochromocytoma," or textword roots of "paraganglioma", "pheochromocytoma", or "phaeochromoctyoma", and the MESH headings "sensitivity and specificity", or "diagnosis", or the textword roots of "sensitiv", "specific", or "diagnos", or the textword "likelihood ratio". We also searched the Web of Science for articles citing the methodologic study of Lenders [49] and hand-searched the abstract books of the 82nd to 84th annual meetings of the Endocrine Society (2000-2002). Two endocrinologists independently screened the titles and abstracts obtained through the electronic search and all full-text articles, deemed potentially relevant by either of the reviewers, were obtained for formal review. After reviewing the full-text articles, both reviewers agreed on which articles would be included in the systematic review.

\section{Assessment of methodologic quality and quality of reporting of included studies and data abstraction}

Each of the two reviewers independently assessed the quality of methodology and reporting of the included studies, using a 25 -item checklist developed by the Standards for Reporting of Diagnostic Studies Accuracy Group (STARD) [62] (Table 1). The two reviewers also independently abstracted the data from published studies in duplicate and consensus was reached on the final data presented. In the case of updated unpublished data from the Mayo Clinic, Rochester, ethics board approval and signed consent was obtained for chart review.

\section{Statistical analyses}

A kappa statistic was calculated to measure agreement between the two reviewers in assessment of methodologic and reporting quality [63]. For sensitivities, specificities, and likelihood ratios, 95\% confidence intervals were calculated using Wilson's method [64]. The Score Method was used for calculation of 95\% CI of likelihood ratios when a zero cell was noted [64]. Likelihood ratios (LRs) predicting the presence of pheochromocytoma given a positive test result (sensitivity/1-specificty) and a negative test result (1-sensitivity/specificity) were calculated for each included study. Of note, a positive LR above 10 and negative LR below 0.1 has been noted to generate large changes from pre-test to post-test probability of disease, often resulting in a large change in patient management; whereas positive LRs between 5 and 10 and negative LRs between 0.1 and 0.2 are considered to generate moderate shifts in pre-test to post-test probability of disease [65-68]. 
Table I: STARD checklist for the reporting of studies of diagnostic accuracy (shortened item description)

\begin{tabular}{|c|c|c|c|c|c|c|c|}
\hline \multirow[t]{2}{*}{ Selection and topic } & \multirow[t]{2}{*}{ Item } & \multicolumn{2}{|c|}{ Mayo } & \multicolumn{2}{|c|}{ NIH } & \multicolumn{2}{|c|}{ Vienna } \\
\hline & & $\mathbf{R} \mid *$ & $\mathbf{R} 2 *$ & $\mathbf{R} \mid *$ & $\mathbf{R} 2 *$ & $\mathbf{R} \mathbf{I}$ & $\mathbf{R} 2 *$ \\
\hline TITLE/ABSTRACT & I. Identify study of diagnostic accuracy & - & - & - & - & • & - \\
\hline INTRODUCTION & 2. State the research question & • & • & • & • & • & - \\
\hline \multicolumn{8}{|l|}{ METHODS } \\
\hline \multirow[t]{4}{*}{ Participants } & 3. Describe study population & • & • & • & - & • & - \\
\hline & 4. Describe participant recruitment & $\bullet$ & $\bullet$ & $\bullet$ & $\bullet$ & & \\
\hline & 5. Describe participant sampling & $\bullet$ & $\bullet$ & & $\bullet$ & & \\
\hline & 6. Describe if prospective or retrospective & - & • & • & - & & - \\
\hline \multirow[t]{5}{*}{ Test Methods } & 7. Reference standard and rationale & $\bullet$ & $\bullet$ & - & - & - & - \\
\hline & 8. Technical specifications described or referenced & • & - & - & • & - & • \\
\hline & 9. Description of rationale for cut-offs for index tests and reference standards & - & - & & - & - & - \\
\hline & 10. Description of the number and training of persons executing the tests & & & & & & \\
\hline & II. Description of blinding of test readers & & & & & & \\
\hline \multirow[t]{2}{*}{ Statistical Methods } & 12. Description of calculations of diagnostic accuracy and uncertainty & • & - & • & - & • & - \\
\hline & 13. Description of calculations of test reproducibility & & & & & & - \\
\hline \multicolumn{8}{|l|}{ RESULTS } \\
\hline \multirow[t]{3}{*}{ Participants } & 14. Description of duration of study & - & - & - & - & & \\
\hline & 15. Description of clinical and demographic description of participants & - & - & - & • & • & • \\
\hline & $\begin{array}{l}\text { 16. Description of the number of participants satisfying inclusion criteria that did } \\
\text { not undergo the index test or reference standard, and why }\end{array}$ & & & - & • & & \\
\hline \multirow[t]{4}{*}{ Test Results } & $\begin{array}{l}\text { 17. Description of the time interval from the index test to the reference standard } \\
\text { and any treatment administered between }\end{array}$ & & & & & & \\
\hline & $\begin{array}{l}\text { 18. Description of the severity of disease in those with the target condition; other } \\
\text { diagnoses in participants without the target condition }\end{array}$ & $\bullet$ & & • & & $\bullet$ & \\
\hline & $\begin{array}{l}\text { 19. A cross-tabulation of the results of the index tests (including indeterminate and } \\
\text { missing tests) }\end{array}$ & $\bullet$ & - & $\bullet$ & • & $\bullet$ & $\bullet$ \\
\hline & 20. Any adverse events from performing the index or reference tests & & & & & & \\
\hline \multirow[t]{4}{*}{ Estimates } & 2l. Estimates of diagnostic accuracy with statistical uncertainty & - & & • & & - & \\
\hline & 22. Description of how indeterminate results were handled & • & • & & & & \\
\hline & 23. Estimates of variability between subgroups of patients, readers, or centres & - & - & - & • & & \\
\hline & 24. Estimates of test reproducibility & & & & & & • \\
\hline DISCUSSION & 25. Discussion of the clinical applicability of the findings & - & • & • & • & • & • \\
\hline
\end{tabular}

$* \mathrm{R} I$ and R2, refer to Reviewer I and 2, •indicates criteria fulfilled (at least in part)

Pooling likelihood ratios was performed if each laboratory used the assay technique of Lenders [49] with an upper limit of a population-based $95 \%$ reference range used as the basis for positivity of the test. Either a free metanephrine or free normetanephrine fraction value had to be above the reference range cut-off, for a test to be considered positive [69]. A chi-squared test of homogeneity (Q-statistic) was performed for pooled studies [70,71]. A random effects model was used for pooling of likelihood ratios using Review Manager 4.1 [66,70,72]. A funnel plot was constructed to visually assess for publication bias of pooled studies $[73,73]$. A separate analysis was performed for all pheochromocytomas and for sporadic pheochromocytomas (those without known genetic predisposition to the disease).

\section{Results}

Studies included in the systematic review

We retrieved 101 unique references; however, 41 of the references were excluded as they were published prior to the specific technique of Lenders being described in 1993 [49], leaving 60 references for consideration of inclusion in the systematic review $[1,4,16-18,22,24,26,44,49$ 61,74-111]. Of these 60 articles, 36 were deemed potentially relevant by either endocrinologist/reviewer $[1,4,16-18,22,24,49-59,61,76,78,82-85,88,89,97$ -

104,104,111]. Thereafter, 13 studies were excluded because of overlap of patients from the same institution or group of institutions in another publication $[49,50,52$ $57,61,82,84,85,111]$. Of the 23 , full-text studies reviewed, 18 were excluded as they lacked new data on sensitivity and specificity of fractionated plasma metanephrine measurements in at least 10 patients with and 10 patients without pheochromocytoma or lacked a methods section $[1,4,16-18,22,24,51,58,59,61,76,78,82$ -

$85,88,89,97,98,100-104]$, or did not cite the Lenders method $[99,100]$.

The remaining studies included in the systematic review were authored by: Lenders et al. [51], Raber et al. [59], and 
Sawka et al. [18], from hereforth to be referred to as the NIH, Vienna, and Mayo papers or studies, respectively.

\section{Summary of methodologic and reporting quality of included studies}

The methodologic and reporting quality of the three included studies was evaluated independently by two endocrinologists using a 25 -item checklist developed by the STARD steering committee (Table 1) [112]. The kappa statistic for measuring agreement between the two reviewers in assessing the STARD items addressed in each study was 0.82 for the Mayo study, 0.65 for the NIH study, 0.60 for the Vienna study.

Specific threats to internal validity of the studies were appraised. In all of the studies, subjects who had signs, symptoms, or imaging characteristics that warranted testing were included (as opposed to asymptomatic controls). However, blinded adjudication of test interpretation and diagnoses was not performed in any of the studies. In terms of limitation of selection bias, consecutive patient recruitment was noted only in the Mayo study [18]. Data was collected prospectively in the NIH study, retrospectively in the Mayo study, and method of data collection was unclear in Vienna study $[18,51,59]$.

In terms of limiting verification bias, only the NIH investigators stated that the results of plasma metanephrine measurements were not used in guiding further evaluation. In the Mayo and Vienna studies, all pheochromocytoma patients had histologic confirmation, whereas in the NIH study, either histologic confirmation or evidence of inoperable metastatic pheochromocytoma on imaging was deemed adequate for diagnosis. In subjects without pheochromocytoma, different criteria were used to define a negative diagnosis in all three studies: alternative diagnosis after subspecialty evaluation in the Mayo study, alternative adrenal histology in the Vienna study, and, in the NIH study, either lack of radiological evidence of a tumor on imaging or pathologic examination of a nonpheochromocytoma adrenal mass, or patient follow-up of 2 years or more. Thus, only in the Vienna study [59], was a histologic gold standard applied to all patients, regardless of disease status.

Overall, the least number of STARD methodologic and reporting criteria were addressed in the case-control design Vienna study [59]. The Vienna study was also the smallest, comparing 17 patients with pheochromocytoma to 14 subjects without pheochromocytoma, and showed the highest diagnostic accuracy (sensitivity and specificity each 100 percent). Of note, the dichotomous nature of case-control designs may overestimate the accuracy of diagnostic tests [113].

\section{Diagnostic efficacy of measurements of fractionated plasma metanephrines in diagnosis of pheochromocytoma} The cut-off values for positivity as well as the conditions of measurement of fractionated plasma metanephrines were slightly different in the Mayo study compared to the NIH and Vienna studies. In the NIH study, the criterion for test positivity was a metanephrine fraction of 0.3 $\mathrm{nmol} / \mathrm{L}$ and/or a normetanephrine fraction of $0.6 \mathrm{nmol} /$ $\mathrm{L}$, based on a laboratory reference range [51]; and the same criterion was used in the Vienna study [59]. In the Mayo study, the criterion for positivity was a metanephrine fraction of $0.5 \mathrm{nmol} / \mathrm{L}$ or a normetanephrine fraction of $0.9 \mathrm{nmol} / \mathrm{L}$, based on a $95 \%$ reference range of Mayo Medical Laboratories [18]. Acetaminophen was generally avoided prior to measurements of plasma free metanephrines in all studies. Furthermore, subjects were supine for at least 20 minutes with an indwelling intravenous cannula in both the NIH and Vienna studies, but not the Mayo study.

Demographics of patients in the included studies were examined (Table 2). A description of patients in the updated (published and unpublished) database from Mayo Clinic Rochester from January 1, 1999 to November 29, 2001 is herein provided. The updated database included the 349 subjects (including 33 patients with pheochromocytoma) that were tested between January 1 , 1999 and November 27, 2000 [18], as well as another 158 subjects (including 23 with pheochromocytoma) that were recruited between November 28, 2000 and November 9,2001 . The newly added 158 subjects were consecutive patients seen at the Mayo Clinic Rochester, who did not have a known familial predisposition to pheochromocytoma, were not tested during the first series, and had complete measurements for fractionated plasma metanephrines as well as 24-hour urinary total metanephrines and catecholamines. In both series, patients without pheochromocytoma were screened in clinical practice because of one or more of the following reasons: hypertension, spells (such as episodes of anxiety, sweating, palpitations, or headache), adrenal abnormality on imaging, previous history of surgically resected pheochromocytoma, or known familial predisposition to pheochromocytoma. Upon combining the published and unpublished data, there were a total of 56 patients with pheochromocytoma (39 of whom were truly sporadic with no known genetic predisposition to pheochromocytoma and no previous history of pheochromocytoma, $70 \%$ ) and 445 subjects without pheochromocytoma (399 with no known genetic predisposition to pheochromocytoma, $90 \%$ percent) (Table 2 ).

The main difference in demographic characteristics between the included studies was that the majority of subjects without pheochromocytoma in the NIH study had a 
Table 2: Demographic characteristics of subjects in included studies

\begin{tabular}{|c|c|c|c|}
\hline Demographic characteristic & Mayo Clinic* & NIH & Vienna \\
\hline Years of recruitment of patients & |999-200| & |994-200| & Unclear \\
\hline Proportion of female gender of all patients & $287 / 507(57 \%)$ & $475 / 858(55 \%)$ & $24 / 31(77 \%)$ \\
\hline Proportion of sporadic pheochromocytoma patients (\%) & $39 / 56(70 \%)$ & $|38 / 2| 4(64 \%)$ & $14 / 17(82 \%)$ \\
\hline $\begin{array}{l}\text { Proportion of non-pheochromocytoma patients with no genetic predisposition to } \\
\text { disease } \dagger\end{array}$ & $399 / 445(90 \%)$ & $305 / 644(47 \%)$ & Unclear \\
\hline Mean age, years (range) of all pheochromocytoma patients & $49(16-83)$ & $33,47 \ddagger(8-78)$ & 46 \\
\hline Mean age, years (range) of all non-pheochromocytoma patients & $52(7-86)$ & $38,47 \ddagger(8-77)$ & 44 \\
\hline
\end{tabular}

*Published Mayo Clinic data was supplemented with new data. † Subjects with sporadic pheochromocytoma and those at risk for sporadic pheochromocytoma had no known genetic predisposition to the disease and no previous history of pheochromocytoma. 6 subjects without pheochromocytoma who had "interfering substances" noted upon measurement of the metanephrine fraction were excluded. $\ddagger$ Mean age of pheochromocytoma patients in NIH study: 33 years for genetically predisposed patients and 47 for sporadic patients. Mean age of nonpheochromocytoma patients in NIH study: 38 for genetically predisposed patients, 47 for sporadic patients.

genetic predisposition to the disease, whereas the majority in the Vienna and Mayo studies did not (Table 2). Furthermore, the non-pheochromocytoma subjects in the Mayo study appeared older with a mean age above 50 years (Table 2). Also, in the Vienna study, all subjects without pheochromocytoma had a known abnormality of the adrenal, whereas this was not the case in all patients in the NIH and Mayo studies.

The diagnostic efficacy of measurements of fractionated plasma metanephrines in detection of pheochromocytoma from the three included studies (including updated unpublished data in the Mayo study) are shown in Table $3[18,51,59]$. For all patients, the sensitivities ranged from $96 \%$ to $100 \%$, and $95 \%$ CI ranged from $82 \%$ to $100 \%$, whereas the specificities ranged from $85 \%$ to $100 \%$ with $95 \%$ CI ranging from $78 \%$ to $100 \%$. For subjects either at risk for or with sporadic pheochromocytoma, the sensitivities ranged from $97 \%$ to $100 \%$ (95\% CI ranged from $79 \%$ to $100 \%)$, whereas the specificities ranged from $82 \%$ to $100 \%$ (95\% CI ranged from $79 \%$ to $100 \%$ ) (Table 3). Furthermore, for all patients, the positive likelihood ratios ranged from 6.31 to 29.17 and the negative LRs ranged from 0.02 to 0.03 (Table 3 ). The positive LRs for all patients with or at risk for sporadic pheochromocytoma (with cured patients who have had a previous diagnosis of pheochromocytoma excluded from the Mayo study) ranged from 6.07 to 29.00 and the negative LRs ranged from 0.031 to 0.03 (Table 3 ).

Upon pooling of the positive likelihood ratios for all patients ( $n=287$ with pheochromocytoma, $n=1103$ without pheochromocytoma), significant heterogeneity was indicated using chi-squared test $\left(\mathrm{X}^{2}=8.20\right.$, degrees of freedom $=2, p=0.017$ ), indicating that studies may have been different secondary to differences in populations studied, assay technique, or reference standard (Figure 1). Although pooling of statistically heterogenous data is of questionable value and should be considered exploratory, the pooled positive likelihood ratio was noted to be 7.86 $(95 \% \mathrm{CI}=5.17,11.94)$, which was significantly higher than $1(z=9.66, p<0.001)$. The pooled estimate of negative likelihood ratios for all patients was 0.02 (95\% CI= $0.01,0.04, \mathrm{z}=-8.60, \mathrm{p}<0.001$ for the value being less than 1$)$, with no evidence of statistical heterogeneity $\left(\mathrm{X}^{2}=\right.$ $0.20, p=0.91$ ) (Figure 2). The funnel plots examining for publication bias were not interpretable as they were limited by very few studies included in the analyses.

Next, we determined the diagnostic efficacy of fractionated plasma metanephrine measurements in patients at risk for sporadic disease. We included 191 pheochromocytoma patients and 718 non-genetically predisposed non-pheochromocytoma patients and found the pooled estimate of a positive likelihood ratio was 5.77 (95\% CI $=4.90,6.81, \mathrm{z}=20.85, \mathrm{p}<0.001$ for the difference being greater than 1 (with no statistically significant evidence of heterogeneity between studies, $\mathrm{X}^{2}=1.84, \mathrm{p}=$ 0.4 ) (Figure 3 ). The pooled estimate of negative likelihood ratios for sporadic subjects was 0.02 (95\% CI= 0.01, $0.07, \mathrm{z}=-6.31, \mathrm{p}<0.001$ for the value being less than 1 ) (no evidence of statistical heterogeneity, $\mathrm{X}^{2}=1.08, \mathrm{p}=$ 0.58) (Figure 4).

\section{Discussion}

Upon systematically reviewing the literature, we have determined that fractionated plasma metanehrine measurements are highly sensitive in detecting pheochromocytoma, although specificity of these measurements may be variable, particularly in testing for sporadic disease. A negative fractionated plasma metanephrine measurement is highly effective in ruling out disease. However, a positive test result only moderately increases suspicion of disease, particularly in low risk subjects being tested for sporadic pheochromocytoma. 
Table 3: Sensitivity and specificity of measurements of fractionated plasma metanephrines

\begin{tabular}{|c|c|c|c|c|}
\hline & Sensitivity $(95 \% \mathrm{CI}) *$ & Specificity $(95 \% \mathrm{Cl}) *$ & $\begin{array}{c}\text { Likelihood ratio of a } \\
\text { positive test* }(95 \% \mathrm{Cl}) *\end{array}$ & $\begin{array}{l}\text { Likelihood ratio of a } \\
\text { negative test* }(95 \% \mathrm{Cl}) *\end{array}$ \\
\hline \multicolumn{5}{|c|}{ ALL PATIENTS } \\
\hline Mayo Clinic $†$ & $96 \%(54 / 56)(88 \%, 99 \%)$ & $85 \%(377 / 445)(81 \%, 88 \%)$ & $6.31(5.04,7.90)$ & $0.02(0.00,0.15)$ \\
\hline NIH & $99 \%(211 / 214)(96 \%, 100 \%)$ & $89 \%(575 / 644)(87 \%, 91 \%)$ & $9.20(7.36,11.5 \mathrm{I})$ & $0.02(0.01,0.05)$ \\
\hline Vienna & $100 \%(17 / 17)(82 \%, 100 \%)$ & $100 \%(14 / 14)(78 \%, 100 \%)$ & $29.17(1.91,445.60)$ & $0.03(0.00,0.44)$ \\
\hline \multicolumn{5}{|c|}{ SPORADIC PATIENTS } \\
\hline Mayo Clinic & $97 \%$ (38/39) (87\%, 100\%) & $84 \%(335 / 399)(80 \%, 87 \%)$ & $6.07(4.83,7.65)$ & $0.03(0.00,0.21)$ \\
\hline NIH & $99 \%(137 / 138)(99 \%, 100 \%)$ & $82 \%(249 / 305)(77 \%, 86 \%)$ & $5.4 \mathrm{I}(4.27,6.85)$ & $0.01(0.00,0.06)$ \\
\hline Vienna & $100 \%(14 / 14)(79 \%, 100 \%)$ & $100 \%(14 / 14)(79 \%, 100 \%)$ & $29.00(1.90,443.27)$ & $0.03(0.00,0.53)$ \\
\hline
\end{tabular}

*Calculated $\uparrow 6$ subjects without pheochromocytoma who had "interfering substances" noted upon measurement of the metanephrine fraction were excluded.

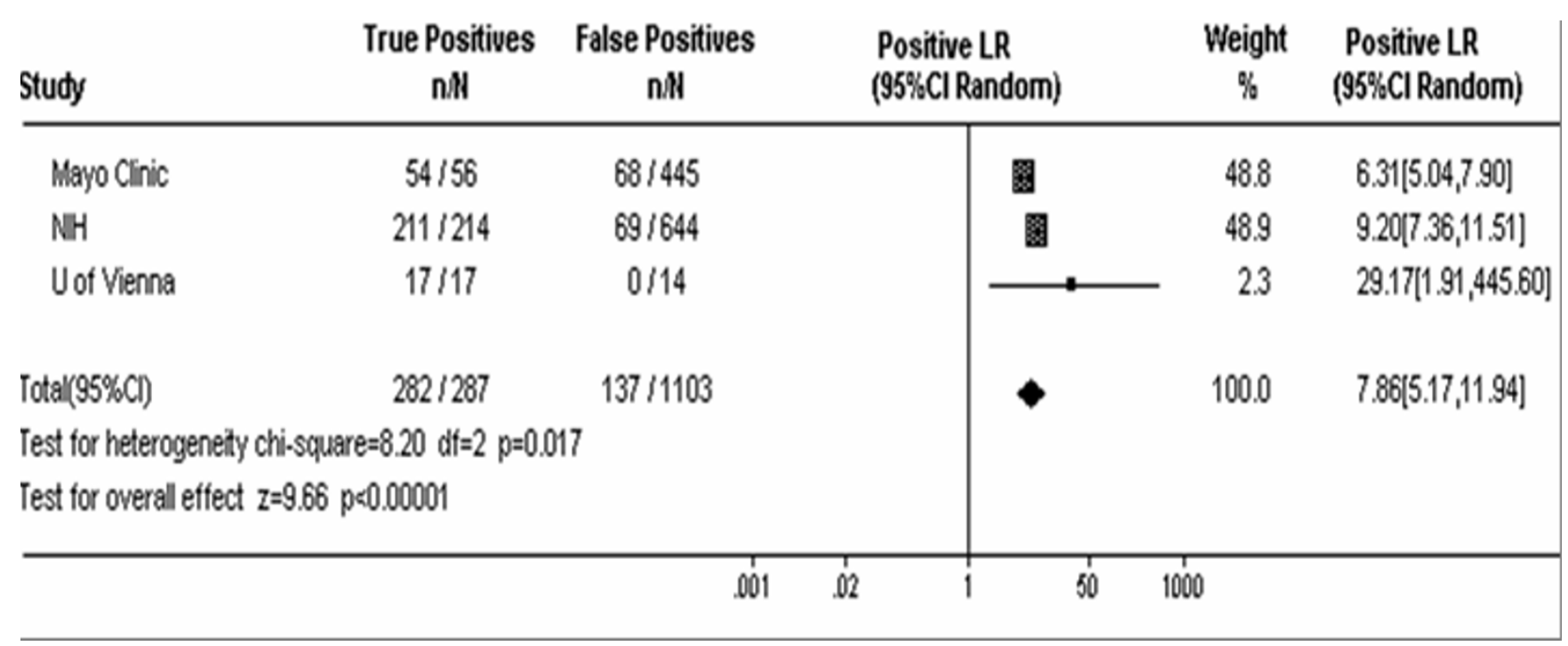

Figure I

Likelihood ratios (LRs) of a positive fractionated plasma metanephrine measurement predicting pheochromocytoma in all patients (including sporadic and genetically-predisposed patients)

Pooled likelihood ratios may be applied in estimation of an individual patient's probability of sporadic pheochromocytoma, given a positive biochemical test result. The pre-test probability of sporadic pheochromocytoma (prevalence) is estimated to be $0.5 \%$ among screened hypertensive patients [114], and 5.1\% among incidentally discovered adrenal masses $>1 \mathrm{~cm}$ in diameter in absence of symptoms of adrenal disease [adrenal "incidentalomas"] [3]. For a patient with positive fractionated plasma metanephrines, the post-test probability of sporadic pheochromocytoma would be $2.8 \%$ in the patient with hypertension, and $23.7 \%$ in the patient with an adrenal incidentaloma. In other words $97.2 \%$ of hypertensive subjects and $76.3 \%$ of subjects with incidentaloma would not be expected to have a pheochromocytoma, in spite of a positive test result. Similarly, we may estimate the probability of sporadic pheochromocytoma, given negative fractionated plasma metanephrine measurements, using the pooled negative likelihood ratio value of 0.02 . For a patient with normal fractionated plasma metanephrine measurements, the post-test probability of sporadic pheochromocytoma would be estimated to be $0.01 \%$ in the patient with hypertension and $0.11 \%$ in the patient with an adrenal incidentaloma. 


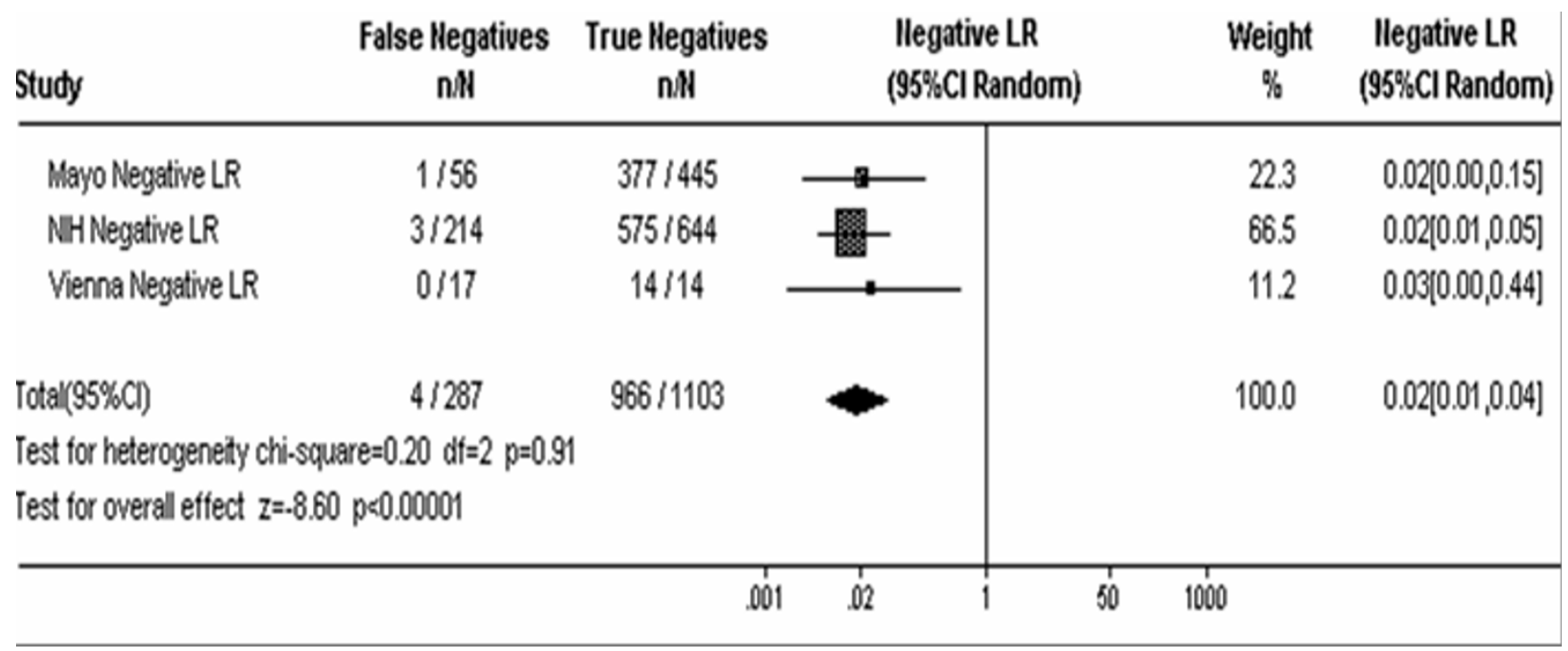

\section{Figure 2}

Likelihood ratios (LRs) of a negative fractionated plasma metanephrine measurement predicting pheochromocytoma in all patients (including sporadic and genetically-predisposed patients)

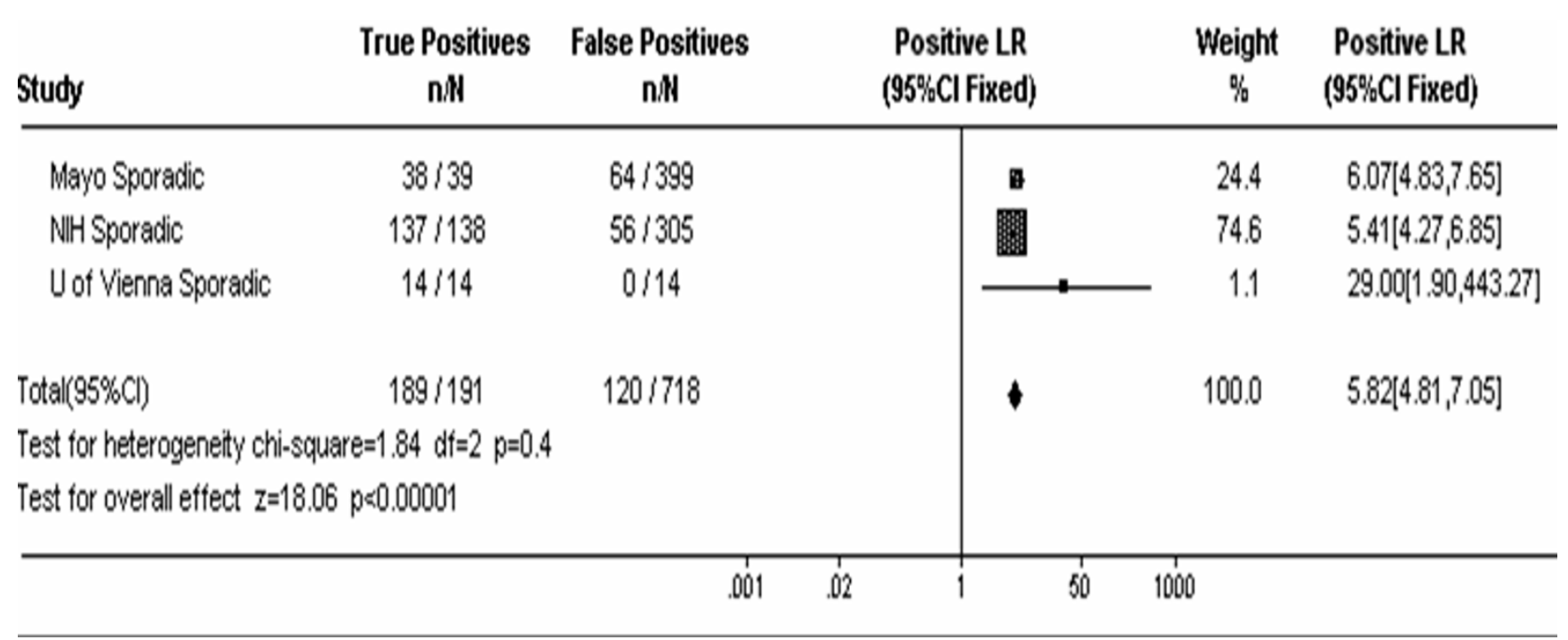

Figure 3

Likelihood ratios (LRs) of a positive fractionated plasma metanephrine measurement predicting pheochromocytoma in patients with sporadic pheochromocytoma or at risk for sporadic pheochromocytoma

Our findings are limited by the fact that data from the included studies may have been subject to multiple methodologic limitations, possibly resulting in over-estimation of the diagnostic efficacy of fractionated plasma metanephrine measurements. Also, many of the patients studied had known genetic predisposition, previously surgically cured disease, or metastatic pheochromocytoma, thereby limiting the external generalizability of our sum- mary. Furthermore, positivity cut-offs were derived somewhat differently between the studies, possibly accounting for the observed heterogeneity of positive likelihood ratios between studies. The criterion for positivity in the NIH and Vienna studies were based on a NIH laboratory reference range [51,59]; whereas a higher criterion was used in the Mayo study, based on a 95\% reference range derived by Mayo Medical Laboratories [18]. The Mayo ref- 


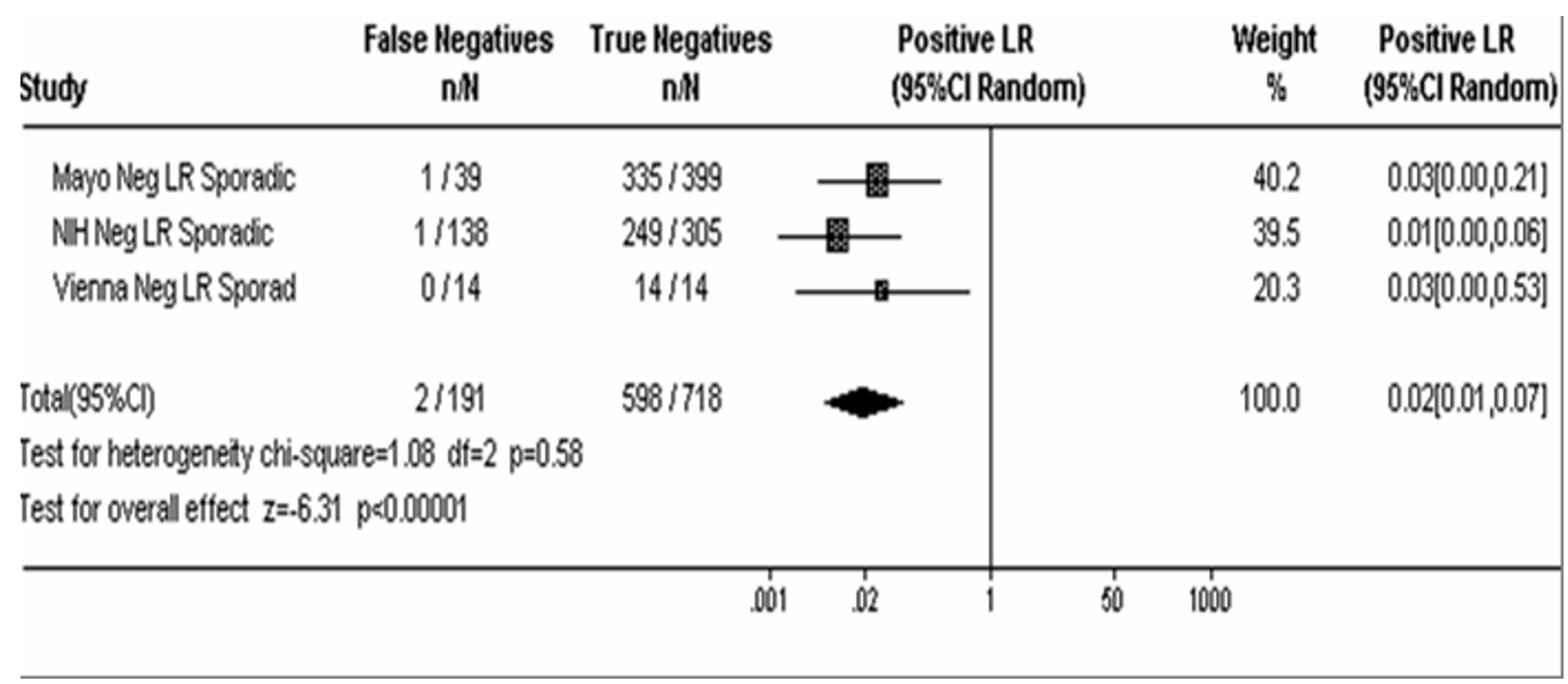

Figure 4

Likelihood ratios (LRs) of a negative fractionated plasma metanephrine measurement predicting pheochromocytoma in patients with sporadic pheochromocytoma or at risk for sporadic pheochromocytoma

erence range has been tested in hypertensive patients who were not subject to indwelling intravenous cannulation or prolonged supine rest, possibly accounting for the slightly higher cut-offs. Indeed, a laboratory medicine tradition has to derive normal ranges from "normal" healthy individuals as such individuals reflect the general population and are easily accessible for study. Such ranges are reflective of "non-disease", but their use may be subject to excessively high rates of false positive tests in subjects with conditions mimicking a disease in question who are likely to be tested clinically (such as patients with refractory hypertension in the case of pheochromocytoma testing). Limitations of deriving "non-disease" ranges in subjects with conditions mimicking a disease in question (such as hypertensive patients in this case) may include decreasing sensitivity of testing and the potential for missing a potentially fatal, treatable diagnosis.

It is notable that data on the efficacy of fractionated plasma metanephrine measurements in detection of pheochromocytoma is limited to only three laboratories with patients recruited from 6 clinical centres. This may be a reflection of the labor-intensive, time-consuming nature of the high performance liquid chromatography and electrochemical detection method as well as the nuisance of potential interference with acetaminophen [115]. A newer method described by Roden et al. may circumvent the acetaminophen interference issue, but is also quite laborintensive and might not be suitable for widespread clinical laboratory use [104]. A method of measurement of fractionated plasma metanephrines using liquid chroma- tography with tandem mass spectrometry shows promise in terms of improved specificity and rapidity of processing of multiple samples [115]. Further clinical study is indicated to validate such newer assays in clinical patient populations.

\section{Conclusions}

Where does this evidence summary leave the physician who is faced with the common clinical scenario of a patient with refractory hypertension or incidentally found adrenal mass? Firstly, the clinician must assess the relative likelihood of pheochromocytoma in each clinical case and decide whether testing is warranted. Decisions for the type of test performed may be subject to clinical availability, cost, and clinical experience of the ordering physician and local laboratory. If measurement of fractionated plasma metanephrines is performed, a positive test result in a high risk setting (such as a genetically predisposed individual or an individual with a known adrenal mass characteristic of pheochromocytoma) or a negative result in a low risk setting (such as a patient with refractory hypertension) is highly predictive of confirming or refuting the diagnosis, respectively. However, a negative result in a high risk setting (such as testing of a genetically predisposed patient or a patient with a known vascular adrenal mass), or a positive result in a low risk setting (such as refractory hypertension) must be interpreted with some caution.

\section{Competing interests}

None declared. 


\section{Authors' contributions}

A.M.S. conceived of the study, developed the study protocol, reviewed the references, abstracted data, analyzed the data, and wrote the paper. LT, ML, LT, AG, APHP, and WFY participated in the design of the study, reviewed the manuscript, and advised on revisions to the manuscript. WFY participated in chart review of Mayo Clinic Rochester patients. LT participated in the data analysis. APHP reviewed the references, and abstracted data.

\section{Acknowledgements}

No research support nor funding was used in this performing this study. A.M. Sawka has received an unrestricted educational grant from HoffmannLa Roche for a Research Fellowship in Health Economics. We appreciate the thoughtful review of this paper by Dr. Wolfgang Raber.

\section{References}

I. Manger WM, Gifford RW: Pheochromocytoma. Journal of Clinical Hypertension 2002, 4(I):62-72.

2. Young WF Jr, Maddox DE: Spells: in search of a cause. Mayo Clinic Proceedings 1995, 70(8):757-765.

3. Young WF Jr: Management approaches to adrenal incidentalomas: A view from Rochester, Minnesota. Endocrinology \& Metabolism Clinics of North America 2000, 29(I):159- 185.

4. Fonseca V, Bouloux PM: Phaeochromocytoma and paraganglioma. Baillieres Clinical Endocrinology \& Metabolism 1993, 7(2):509-544.

5. Young WF Jr: Pheochromocytoma and primary aldosteronism. Cancer Treatment \& Research 1997, 89:239-26I.

6. Beard CM, Sheps SG, Kurland LT, Carney JA, Lie JT: Occurrence of pheochromocytoma in Rochester, Minnesota, 1950 through 1979. Mayo Clinic Proceedings 1983, 58(1 2):802-804.

7. Stenstrom G, Svardsudd K: Pheochromocytoma in Sweden 1958-198I. An analysis of the National Cancer Registry Data. Acta Medica Scandinavica 1986, 220(3):225-232.

8. Hartley L, Perry-Keene D: Phaeochromocytoma in Queensland - 1970-83. Australian \& New Zealand Journal of Surgery 1985, 55(5):47| -475 .

9. Andersen GS, Toftdahl DB, Lund JO, Strandgaard S, Nielsen PE: The incidence rate of phaeochromocytoma and Conn's syndrome in Denmark, 1977-1981. Journal of Human Hypertension 1988, 2(3): 187-189.

10. Fernandez-Calvet L, Garcia-Mayor RV: Incidence of pheochromocytoma in South Galicia, Spain. Journal of Internal Medicine 1994, 236(6):675-677.

II. Neumann HP, Bausch B, McWhinney SR, Bender BU, Gimm O, Franke $G$, et al:: Germ-line mutations in nonsyndromic pheochromocytoma. New England Journal of Medicine 2002, 346(19): I 1459-I 466.

12. Bender BU, Gutsche M, Glasker S, Muller B, Kirste G, Eng C, et al.: Differential genetic alterations in von Hippel-Lindau syndrome-associated and sporadic pheochromocytomas. Journal of Clinical Endocrinology \& Metabolism 2000, 85(I 2):4568-4574.

13. Young WF Jr: Pheochromocytoma: 1926-1993. Trends in Endocrinolology and Metabolism 1993, 4:122-1 27.

14. Young WF Jr: Pheochromocytoma and primary aldosteronism: diagnostic approaches. Endocrinology \& Metabolism Clinics of North America 1997, 26(4):80 I-827.

15. Graham PE, Smythe GA, Edwards GA, Lazarus L.: Laboratory diagnosis of phaeochromocytoma: which analytes should we measure? Annals of Clinical Biochemistry 1993, 30(Pt 2): 129-134.

16. Gerlo EA, Sevens C.: Urinary and plasma catecholamines and urinary catecholamine metabolites in pheochromocytoma: diagnostic value in 19 cases. Clinical Chemistry 1994, 40(2):250-256.

17. Witteles RM, Kaplan EL, Roizen MF: Sensitivity of diagnostic and localization tests for pheochromocytoma in clinical practice. Archives of Internal Medicine 2000, 160( I6):2521-2524.

18. Sawka AM, Jaeschke R, Singh RJ, Young WF Jr: A comparison of biochemical tests for pheochromocytoma: measurement of fractionated plasma metanephrines compared with the combination of 24-hour urinary metanephrines and catecholamines. Journal of Clinical Endocrinology \& Metabolism 2003, 88(2):553-558.

19. Sheps SG, Jiang NS, Klee GG: Diagnostic evaluation of pheochromocytoma. Endocrinology \& Metabolism Clinics of North America 1988, I7(2):397-4I4.

20. Mannelli M, lanni L, Cilotti A, Conti A: Pheochromocytoma in Italy: a multicentric retrospective study. European Journal of Endocrinology 1999, I4 I(6):619-624.

21. Gifford RW Jr, Manger WM, Bravo EL: Pheochromocytoma. Endocrinology \& Metabolism Clinics of North America 1994, 23(2):387-404.

22. Peplinski GR, Norton JA: The predictive value of diagnostic tests for pheochromocytoma. Surgery 1994, I I6(6): I I0 I-I I 09.

23. Bravo EL: Circulating and urinary catecholamines in pheochromocytoma. New England Journal of Medicine 1979, 30I(I3):682-686.

24. Candito M, Billaud E, Chauffert M, Cottet-Emard JM, Desmoulin D, Garnier JP, et al.: Biochemical diagnosis of pheochromocytoma and neuroblastomas. Annales de Biologie Clinique 2002, 60(1): $15-36$.

25. Jibiki K, Demura H, Naruse M, Demura R, Ito Y, Sakurai H, et al.: Biochemical diagnosis of pheochromocytoma by determining normetanephrine and metanephrine concentrations in single voided urine. Nippon Naibunpi Gakkai Zasshi - Folia Endocrinologica Japonica 1988, 64(8):707-716.

26. Mediavilla Garcia JD, Leon-Ruiz L, Hidalgo TC, Lopez de la Torre Casares, Piedrola MG, Pinel JP, et al:: Usefulness of the clonidine test for the diagnosis of pheochromocytoma. Revista Clinica Espanola 200I, 201 (5):245-248.

27. Bravo EL: Evolving concepts in the pathophysiology, diagnosis, and treatment of pheochromocytoma. Endocrine Reviews 1994, I5(3):356-368

28. linuma K, Ikeda I, Ogihara T, Hashizume K, Kurata K, Kumahara Y: Radioimmunoassay of metanephrine and normetanephrine for diagnosis of pheochromocytoma. Clinical Chemistry 1986, 32(10): 1879-83.

29. Juan D: Pheochromocytoma: Clinical manifestations and diagnostic tests. Urology 198I, I7(1): I-12.

30. Zoghbi F, Landault C, Salmon N, Legrand JC: Catecholamines and their derivatives in the study of pheochromocytoma. Annales de Medecine Interne 1983, 134(3):230-232.

31. Taylor RL, Singh RJ.: Validation of liquid chromatography-tandem mass spectrometry method for analysis of urinary conjugated metanephrine and normetanephrine for screening of pheochromocytoma. Clinical Chemistry 2002, 48(3):533-539.

32. Hsiao RJ, Parmer RJ, Takiyyuddin MA, O'Connor DT: Chromogranin A storage and secretion: sensitivity and specificity for the diagnosis of pheochromocytoma. Medicine I99I, 70(I):33-45.

33. d'Herbomez M, Gouze V, Huglo D, Nocaudie M, Pattou F, Proye C, et al: Chromogranin A assay and (13I)I-MIBG scintigraphy for diagnosis and follow-up of pheochromocytoma. Journal of Nuclear Medicine 200I, 42(7):993-997.

34. Grossman E, Goldstein DS, Hoffman A, Keiser HR: Glucagon and clonidine testing in the diagnosis of pheochromocytoma. Hypertension 199I, I7(6:Pt I):733-74I.

35. Plouin PF, Chatellier G, Delahousse M, Rougeot MA, Duclos JM, Pagny JY, et al.: Detection, diagnosis and localization of pheochromocytoma. 77 cases in a population of 21,420 hypertensive patients. Presse Medicale 1987, 16(44):221 I-22I5.

36. Plouin PF, Duclos JM, Menard J, Comoy E, Bohuon C, Alexandre JM: Biochemical tests for diagnosis of phaeochromocytoma: Urinary versus plasma determinations. British Medical Journal I98I, 282(6267):853-854.

37. Plouin PF, Chatellier G, Grouzmann E, Azizi M, Denolle T, Comoy E, et al.: Plasma neuropeptide $\mathbf{Y}$ and catecholamine concentrations and urinary metanephrine excretion in patients with adrenal or ectopic phaeochromocytoma. Journal of Hypertension - Supplement 1991, 9(6):S272-S273.

38. Hanna A, Prosser C, LeGatt D, Froment S, Cembrowski GS: Medical allowable imprecision in measuring urinary metanephrines. Clinical Biochemistry 2001, 34(2): 159-60.

39. Ross GA, Newbould EC, Thomas J, Bouloux PM, Besser GM, Perrett $D$, et al.: Plasma and 24 h-urinary catecholamine concentrations in normal and patient populations. Annals of Clinical Biochemistry 1993, 30(Pt I):38-44. 
40. Ito Y, Obara T, Okamoto T, Kanbe M, Tanaka R, lihara M, et al.: Efficacy of single-voided urine metanephrine and normetanephrine assay for diagnosing pheochromocytoma. World Journal of Surgery 1998, 22(7):684-688.

4I. Kaplan NM, Kramer NJ, Holland OB, Sheps SG, Gomez-Sanchez C: Single-voided urine metanephrine assays in screening for pheochromocytoma. Archives of Internal Medicine 1977 137(2): 190-193.

42. Willemsen IJ, Ross HA, Wolthers BG, Sweep CG, Kema IP: Evaluation of specific high-performance liquid-chromatographic determinations of urinary metanephrine and normetanephrine by comparison with isotope dilution mass spectrometry. Annals of Clinical Biochemistry 200I, 38(Pt:6):6-30.

43. Heron E, Chatellier G, Billaud E, Foos E, Plouin PF.: The urinary metanephrine-to-creatinine ratio for the diagnosis of pheochromocytoma. Annals of Internal Medicine 1996, 125(4):300-303.

44. Peaston RT, Lennard TW, Lai LC: Overnight excretion of urinary catecholamines and metabolites in the detection of pheochromocytoma. Journal of Clinical Endocrinology \& Metabolism 1996, 8I(4): I378-I384.

45. Mulinari RA, Zanella MT, Guerra EM, Kohlmann O Jr, Saad Cl, Andriollo A, et al:: The clonidine test for the diagnosis of pheochromocytoma: the usefulness of urinary metanephrine measurements. Brazilian Journal of Medical \& Biological Research 1987, 20(I):43-46.

46. Gardet V, Gatta B, Simonnet G, Tabarin A, Chene G, Ducassou D, et al.: Lessons from an unpleasant surprise: a biochemical strategy for the diagnosis of pheochromocytoma. Journal of Hypertension 200I, I9(6): 1029-1035.

47. Letizia C, De Toma G, Caliumi C, Cerci S, Massa R, Loria RD, et al: Plasma adrenomedullin concentrations in patients with adrenal pheochromocytoma. Hormone \& Metabolic Research 200I, 33(5):290-294.

48. Mornex R, Peyrin L, Pagliari R, Cottet-Emard JM: Measurement of plasma methoxyamines for the diagnosis of pheochromocytoma. Hormone Research 1991, 36(5-6):220-226.

49. Lenders JW, Eisenhofer G, Armando I, Keiser HR, Goldstein DS, Kopin IJ: Determination of metanephrines in plasma by liquid chromatography with electrochemical detection. Clinical Chemistry 1993, 39(I):97-103.

50. Lenders JW, Keiser HR, Goldstein DS, Willemsen JJ, Friberg P, Jacobs MC, et al.: Plasma metanephrines in the diagnosis of pheochromocytoma. Annals of Internal Medicine 1995 , 123(2): $101-109$

5I. Lenders JW, Pacak K, Walther MM, Linehan WM, Mannelli M, Friberg $P$, et al.: Biochemical diagnosis of pheochromocytoma: which test is best? Journal of the American Medical Association 2002, 287(I I): I 427-I 434

52. Lenders JW, Pacak K, Eisenhofer G: New advances in the biochemical diagnosis of pheochromocytoma: moving beyond catecholamines. Annals of the New York Academy of Sciences 2002, 970:29-40.

53. Eisenhofer G, Walther MM, Huynh TT, Li ST, Bornstein SR, Vortmeyer A, et al.: Pheochromocytomas in von Hippel-Lindau syndrome and multiple endocrine neoplasia type 2 display distinct biochemical and clinical phenotypes. Journal of Clinical Endocrinology \& Metabolism 200I, 86(5): 1999-2008.

54. Eisenhofer G, Lenders JW, Pacak K: Choice of biochemical test for diagnosis of pheochromocytoma: validation of plasma metanephrines. Current Hypertension Reports 2002, 4(3):250-255.

55. Eisenhofer G, Walther M, Keiser HR, Lenders JW, Friberg P, Pacak K: Plasma metanephrines: a novel and cost-effective test for pheochromocytoma. Brazilian Journal of Medical \& Biological Research 2000, 33(10): II57-1169.

56. Eisenhofer G, Keiser H, Friberg P, Mezey E, Huynh TT, Hiremagalur $B$, et al.: Plasma metanephrines are markers of pheochromocytoma produced by catechol-O-methyltransferase within tumors. Journal of Clinical Endocrinology \& Metabolism 1998, 83(6):2175-2185.

57. Eisenhofer G, Lenders JW, Linehan WM, Walther MM, Goldstein DS, Keiser HR: Plasma normetanephrine and metanephrine for detecting pheochromocytoma in von Hippel-Lindau disease and multiple endocrine neoplasia type 2. New England Journal of Medicine 1999, 340(24): 1872-1879.
58. Eisenhofer G, Rundquist B, Aneman A, Friberg P, Dakak N, Kopin IJ, et al: Regional release and removal of catecholamines and extraneuronal metabolism to metanephrines. Journal of Clinical Endocrinology \& Metabolism 1995, 80( I 0):3009-30I7.

59. Raber W, Raffesberg W, Bischof M, Scheuba C, Niederle B, Gasic S, et al:: Diagnostic efficacy of unconjugated plasma metanephrines for the detection of pheochromocytoma. Archives of Internal Medicine 2000, 160(19):2957-2963.

60. Weise M, Merke DP, Pacak K, Walther MM, Eisenhofer G: Utility of plasma free metanephrines for detecting childhood pheochromocytoma. Journal of Clinical Endocrinology \& Metabolism 2002, 87(5): 1955-1960.

61. Pacak K, Linehan WM, Eisenhofer G, Walther MM, Goldstein DS: Recent advances in genetics, diagnosis, localization, and treatment of pheochromocytoma. Annals of Internal Medicine 200I, 134(4):315-329.

62. Bossuyt PM, Reitsma JB, Bruns DE, Gatsonis CA, Glasziou PP, Irwig LM, et al.: Towards complete and accurate reporting of studies of diagnostic accuracy: The STARD Initiative. Annals of Internal Medicine 2003, I 38(I):40-44.

63. Rosner B: Fundamentals of Biostatistics Fifth edition. Pacific Grove, CA: Duxbury; 2000.

64. Altman D, Machin D, Bryant T, Gardner M: Statistics with Confidence Second edition. London, UK: British Medical Journal Books; 2000.

65. Jaeschke R, Guyatt G, Sackett D, for the Evidence-Based Medicine Working Group: Users' guide to the medical literature: III. How to use an article about a diagnostic test. B. What are the results and will they help me in caring for my patients? Journal of the American Medical Association 1994, 27 I:703-707.

66. Deeks JJ: Systematic reviews in health care: Systematic reviews of evaluations of diagnostic and screening tests. British Medical Journal 200I, 323(7305): I57-I 62.

67. Khan KS, Dinnes J, Kleijnen J: Systematic reviews to evaluate diagnostic tests. European Journal of Obstetrics, Gynecology, \& Reproductive Biology 200I, 95(1):6-II.

68. Empson MB: Statistics in the pathology laboratory: diagnostic test interpretation. Pathology 2002, 34(4):365-369.

69. Macaskill P, Walter SD, Irwig L, Franco EL: Assessing the gain in diagnostic performance when combining two diagnostic tests. Statistics in Medicine 2002, 2 I ( I 7):2527-2546.

70. DerSimonian R, Laird N: Meta-analysis in clinical trials. Controlled Clinical Trials 1986, 7(3): I77-I88.

7I. Takkouche B, Cadarso-Suarez C, Spiegelman D: Evaluation of old and new tests of heterogeneity in epidemiologic meta-analysis. American Journal of Epidemiology 1999, I 50(2):206-I5.

72. Boissel J, Cucherat M: The meta-analysis of diagnostic test studies. European Radiology 1998, 8(3):484-487.

73. Song F, Khan KS, Dinnes J, Sutton AJ: Asymmetric funnel plots and publication bias in meta-analyses of diagnostic accuracy. International Journal of Epidemiology 2002, 3 I (I):88-95.

74. Alves A, Scatton O, Dousset B: Diagnostic and therapeutic strategy for an incidental finding of an adrenal mass. Journal de Chirurgie 2002, I39(4):205-2I3.

75. Arnaldi G, Masini AM, Giacchetti G, Taccaliti A, Faloia E, Mantero F: Adrenal incidentaloma. Brazilian Journal of Medical \& Biological Research 2000, 33(10): II77-II89.

76. Arnault-Ouary G, Chatal JF, Charbonnel B: Pheochromocytoma. Revue du Praticien 1998, 48(7):744-748.

77. Berard E, Candito M, Diaine B, Kurzenne JY, Bekri S, Chambon P, et al.: Increased urinary catecholamines in a hypertensive child with renal artery stenosis. Pediatric Nephrology 1996, I0(6):76I-763.

78. Bravo EL: Plasma or urinary metanephrines for the diagnosis of pheochromocytoma? That is the question. Annals of Internal Medicine 1996, I 25(4):33I-332.

79. Chen H, Doppman JL, Chrousos GP, Norton JA, Nieman LK, Udelsman R: Adrenocorticotropic hormone-secreting pheochromocytomas: the exception to the rule. Surgery 1995, I I 8(6):988-994.

80. Corsello SM, Della CS, Bollanti L, Rufini V, Rota CA, Danza F, et al. Incidentally discovered adrenal masses: a functional and morphological study. Experimental \& Clinical Endocrinology 1993, I0I(3): |3|-| 37.

8I. Dwamena BA, Zempel S, Klopper JF, Van Heerden B, Wieland D, Shapiro B: Brain uptake of iodine- I3 I metaiodobenzylguanidine 
following therapy of malignant pheochromocytoma. Clinical Nuclear Medicine 1998, 23(7):44I-445.

82. Eisenhofer G: Biochemical Diagnosis of PheochromocytomaIs it Time to Switch to Plasma-Free Metanephrines? Journal of Clinical Endocrinology \& Metabolism 2003, 88(2):550-552.

83. Elijovich F: Plasma metanephrines in the diagnosis of pheochromocytoma. Annals of Internal Medicine 1996, I 24(7):694-695.

84. Friberg P: Plasma metanephrine measurements make the diagnosis of pheochromocytoma easier. Lakartidningen 1998, 95(2I):2482-2485.

85. Friberg P: Pheochromocytoma: The risk to miss diagnosis of severe disease is reduced when free metanephrines are measured in plasma. Lakartidningen 1998, 95(47):5342-5343.

86. Godfrey JA, Rickman OB, Williams AW, Thompson GB, Young WF Jr: Pheochromocytoma in a patient with end-stage renal disease. Mayo Clinic Proceedings 200I, 76(9):953-957.

87. Gourgiotis L, Sarlis NJ, Reynolds JC, VanWaes C, Merino MJ, Pacak K: Localization of Medullary Thyroid Carcinoma Metastasis in a Multiple Endocrine Neoplasia Type 2A Patient by 6[(18)F]-Fluorodopamine Positron Emission Tomography. Journal of Clinical Endocrinology \& Metabolism 2003, 88(2):637-64I.

88. Grouzmann E, Fathi M, Gillet M, de Torrente A, Cavadas C, Brunner $\mathrm{H}$, et al:: Disappearance rate of catecholamines, total metanephrines, and neuropeptide $Y$ from the plasma of patients after resection of pheochromocytoma. Clinical Chemistry 200I, 47(6): $1075-1082$

89. Lenz T, Gossmann J, Schulte KL, Salewski L, Geiger H: Diagnosis of pheochromocytoma. Clinical Laboratory 2002, 48(I-2):5-18.

90. Linos DA: Management approaches to adrenal incidentalomas (adrenalomas). A view from Athens, Greece. Endocrinology \& Metabolism Clinics of North America 2000, 29(1): 14I-I57.

91. Madrid Garcia FJ, Rivas Escudero JA, Parra ML, Sanchez SE, Gomez CS, Garcia AJ: Extra-adrenal pheochromocytoma. Report of a case. Archivos Espanoles de Urologia 2000, 53(3):260-264.

92. Mannelli M, Pupilli C, Lanzillotti R, lanni L: Diagnostic problems in pheochromocytoma [Meeting abstract]. CANCERLIT 1995.

93. Nakai T: Advances in diagnostic procedures for detection of pheochromocytoma. Rinsho Byori - Japanese Journal of Clinical Pathology 1993, 4I(2): I 17-I22.

94. Nguyen L, Niccoli-Sire P, Caron P, Bastie D, Maes B, Chabrier G, et al.: Pheochromocytoma in multiple endocrine neoplasia type 2: a prospective study. European Journal of Endocrinology 200I, 1 44(I):37-44.

95. Nishikawa M, Masaki M, Masaki H, Shiomi K, Tsutsumi Y, Okuhira M, et al:: Zollinger-Ellison syndrome and pheochromocytoma. Report of a case. Hormone \& Metabolic Research 1993, 25(3): $180-183$.

96. Pacak K, Goldstein DS, Doppman JL, Shulkin BL, Udelsman R, Eisenhofer G: A "pheo" lurks: novel approaches for locating occult pheochromocytoma. Journal of Clinical Endocrinology \& Metabolism 200I, 86(8):364I-3646.

97. Pacak K, Eisenhofer G, Carrasquillo JA, Chen CC, Li ST, Goldstein DS: 6-[18F]fluorodopamine positron emission tomographic (PET) scanning for diagnostic localization of pheochromocytoma. Hypertension 200I, 38(I):6-8.

98. Pallant A, Mathian B, Prost L, Theodore C, Patricot MC: Determination of plasma methoxyamines. Clinical Chemistry \& Laboratory Medicine 2000, 38(6):5I3-5I7.

99. Peyrin L, Mornex R: Biological diagnosis of pheochromocytoma: impact of technological improvement. Annales de Biologie Clinique 1993, 5 I ( I0-I I):835-65.

100. Peyrin L, Cottet-Emard JM, Pagliari R, Cottet-Emard RM, Badet C, Mornex R: Plasma methoxyamines assay: a practical advance for the diagnosis of pheochromocytoma. Pathologie et Biologie 1994, 42(9):847-854.

I0I. Peyrin L, Cottet-Emard JM, Cottet-Emard RM, Vouillarmet A: The diagnosis of atypical pheochromocytoma: a challenge for the biologist as well. Pathologie et Biologie 200I, 49(3):247-254.

102. Plouin PF, Gimenez-Roqueplo AP, La Batide AA, Salenave S, Duclos $J M$ : Recent progress in the diagnosis, prognostic evaluation and treatment of pheochromocytomas. Revue de Medecine Interne 2000, 2 I ( I 2): I 075-1085.

103. Roden M: How to detect pheochromocytomas? - the diagnostic relevance of plasma free metanephrines. Wiener Klinische Wochenschrift 2002, I I4(7):246-25I.

104. Roden M, Raffesberg W, Raber W, Bernroider E, Niederle B, Waldhausl W, et al:: Quantification of unconjugated metanephrines in human plasma without interference by acetaminophen. Clinical Chemistry 200I, 47(6): I06I-I067.

105. Sato M, Watanabe T, Ashikaga T, Taneda T, Yamawake N, Nishizaki $\mathrm{M}$, et al.: Adrenocorticotropic hormone-secreting pheochromocytoma. Internal Medicine 1998, 37(4):403-406.

106. Schmidt J, Mohr VD, Metzger P, Zirngibl H: Posttraumatic hypertension secondary to adrenal hemorrhage mimicking pheochromocytoma: case report. Journal of Trauma-Injury Infection \& Critical Care 1999, 46(5):973-975.

107. Sleilati GG, Kovacs KT, Honasoge M: Acromegaly and pheochromocytoma: report of a rare coexistence. Endocrine Practice 2002, 8(I):54-60.

108. Smythe GA, Drew CM: REPCAT: desktop expert system for interpreting and validating laboratory data for pheochromocytoma diagnosis with the database application Omnis 7. Clinical Chemistry 1997, 43( I): 134-40.

109. Stewart MF, Reed P, Weinkove C, Moriarty KJ, Ralston AJ: Biochemical diagnosis of phaeochromocytoma: two instructive case reports. Journal of Clinical Pathology 1993, 46(3):280-282.

I 10. Tirri R, Casiere D, Mattera E, Guarino G, lacono G, Federico P: The nephrotic syndrome and pheochromocytoma. A report of a rare clinical case. Clinica Terapeutica 1994, 145(9): 199-203.

III. Eisenhofer G, Friberg P, Pacak K, Goldstein DS, Murphy DL, Tsigos C, et al:: Plasma metadrenalines: do they provide useful information about sympatho-adrenal function and catecholamine metabolism? Clinical Science 1995, 88(5):533-542.

I 12. Bossuyt PM, Reitsma JB, Bruns DE, Gatsonis CA, Glasziou PP, Irwig LM, et al.: The STARD statement for reporting studies of diagnostic accuracy: explanation and elaboration. Annals of Internal Medicine Online 2003, 138(1):WI-I2.

I 13. Lijmer JG, Mol BW, Heisterkamp S, Bonsel GJ, Prins MH, van der Meulen $\mathrm{JH}$, et al.: Empirical evidence of design-related bias in studies of diagnostic tests. Journal of the American Medical Association 1999, 282(1 I): 106I-1066.

114. Manger WM, Gifford RW Jr: Clinical and Experimental Pheochromocytoma Cambridge, MA: Blackwell Science; 1996.

1 15. Lagerstedt SA, O'Kane DJ, Singh RJ: Measurement of plasma free metanephrine and normetanephrine by liquid chromatography-tandem mass spectrometry for diagnosis of pheochromocytoma. Clinical Chemistry 2004, 50(3):603-6II

\section{Pre-publication history}

The pre-publication history for this paper can be accessed here:

\section{http://www.biomedcentral.com/1472-6823/4/2/prepub}

Publish with Biomed Central and every scientist can read your work free of charge

"BioMed Central will be the most significant development for disseminating the results of biomedical research in our lifetime. "

Sir Paul Nurse, Cancer Research UK

Your research papers will be:

- available free of charge to the entire biomedical community

- peer reviewed and published immediately upon acceptance

- cited in PubMed and archived on PubMed Central

- yours - you keep the copyright

Submit your manuscript here:

http://www.biomedcentral.com/info/publishing_adv.asp
BioMedcentral 